\title{
Social Spacing, Organizational Development and Network Utility of Chinese Business Organizations in Cambodia
}

\author{
Shihlun Allen Chen ${ }^{1}$ \\ Sun Yat-sen University
}

\begin{abstract}
Chain migration has been one of the most explanatory paradigms in explaining transnational ethnic population movement while economic push-pull serves as the driving force to run the wheel. Thus geo-spatial kinship has been used to consolidate the trust and altruistic relations in such a system. However, the problem is that, does this neoliberal migration pattern just be formed and performed from very beginning of the migration flow as it assumes? How does it evolve and how does it get to mature into its present dynamic structure? To answer, this paper uses author's fieldwork data from Cambodia's ethnic Chinese community as the case to establish an ethnic network system of social spacing, organizational life cycle and ethnic network utility based on the case of Chinese communities in Cambodia. The correlation between ethnic social spaces and social organizations is concluded to explain how various identity variations are utilized in the five different stages of an ethnically organized life cycle. It tracks back how diaspora communities and ethnic networks begin the process of self-organization among members starting at early stage of informal interest groups and transforming into substantialized, normalized, formalized and legalized registered ethnic organizations that have access to government resources, transnational networks, and the local ethnic community.
\end{abstract}

\section{Ethnic Power and Network Utility of Chinese}

Chain migration has been one of the most explanatory paradigms in explaining transnational ethnic population movements while economic push-pull serves as the driving force to run the wheel. Thus geo-spatial kinship, or ethnic tie in a broad sense, has been used to consolidate the trust and altruistic relations in the international trade and transnational migration flow (Landa, 1994; Redding, 1995). However, the problem is that, does this neoliberal migration pattern just be formed and performed from the very beginning of the migration flow as it assumes? How does it evolve and how does it get to mature into its present dynamic demographic structure, taking overseas Chinese migration in Southeast Asian countries as an example?

Driven by the economic pushing and pulling forces, people move across the borderline in pursuance of a better life (Parkins, 2010). One of the theoretical paradigms that best explain this transnational ethnic population movement is Chain migration theory (MacDonald \& MacDonald, 1964; McKeown, 1999; Liu, 2005). During the transnational migration process, kinship built on the same ethnic/cultural roots or geo-spatial closeness has been the foundation of mutual trust, cooperation, even altruistic behaviors (Landa, 1994; Redding, 1995). However, the migration pattern is not a static model across time. Instead, 
it evolves along the time and finally reaches the current pattern. This article discusses how the overseas Chinese's migration model in Cambodia evolved and matured along the time and developed into the present dynamic demographic structure.

This article uses the author's ethnographic fieldwork data which was collected from Cambodia's ethnic Chinese communities during 2013-2015 to establish an experimental hypothesis on the life cycle of Chinese ethnic organizations about various types of sub-ethnic groups within the community. This organizational life cycle explains how a migratory community first takes shape through a few pioneer individuals due to rational economic reasons. After that, a loose and individualistic migration community bridges population transition from the home country to the new settlements; and then these people develop an organic power structure with various informal social groups. These informal social organizations eventually evolve into formal social organizations, and serve as the nerve system in the migrated community. These informal and formal social organizations carry out functions such as resource mobilization, identity socialization, ethnic consolidation, and nostalgia-curing. Because of their unique status and wide accessibility within the community, the formal social organizations are often adapted and utilized by both settlement and home states in international and domestic political affairs.

This Ethnic Organizational Life Cycle can be seen as the developing process of the ethnic network in a chronic sense. In terms of spatial network utility, the connection between various social spaces with specific sub-types of social circles/groups among the entire Overseas Chinese community in Cambodia and their inter-group relations then fabricate the ethnic Chinese network. This article discusses the development of both Taiwanese and Mainland Chinese communities in Cambodia as examples to illustrate two arguments later discussed in the article. In the first part, we discuss the development process of the overseas Chinese network in Cambodia, particularly the network of new Chinese migrants- how it actually a grass-root and bottom-up grouping process based on the social dynamics of multiple sub-ethnic groups' self-governing and organizing utilities. Secondly, the Chinese ethnic network is grounded on the social complexity of ethnic social spaces and social groupings, which varies based on the sub-ethnic group identities such as hometown, dialects and regional social belongingness. Thus, the author proposes that this Ethnic Organizational Life Cycle is the core force that shapes ethnic network and sculptures the ethnic Chinese network across national boundaries.

In order to fully embody the ethnic organizational life cycle theory, the author uses both Cambodia's Chinese ethno-history and the author's ethnographic field data to demonstrate how this process was fully exemplified in Cambodia's Chinese immigrant community. Furthermore, the interviews and ethnographic materials collected by the author strongly support the argument that such organizational life cycle explains the developing process of transnational ethnic network in the new settlement. In this case, the Chinese immigrant community in Cambodia is examined in order to provide a new pattern in explaining the transnational chain migration beyond economic forces. The ethnic network constituted by social organizations and its various development phases can be viewed as an alternative force in driving the overseas Chinese population's movement between their homeland and Cambodia.

\section{From Social Spaces to Social Groups: A Static Case of Taiwanese in Cambodia}

Long before I started my 2013's 17 month-long fieldwork in Phnom Penh, I have known that Chung Hsin Hotel has been the most common choice for many Chinese business and leisure travelers to Cambodia. Since its opening in 1998, Chung Hsin Hotel has been the first stop and the preferred accommodation solution for many Taiwanese and Chinese when they visit Cambodia. The building is owned and operated by a Taiwanese entrepreneur and staffed with Mandarin-speaking employees. Taiwanese and other Mandarin-speaking customers find it comfortable and convenient since the whole building was designed and constructed by Taiwanese and almost all construction materials were imported from Taiwan. Even the power socket and switches were of "Taiwanese-style." According to their customers, the hotel is not only close to the downtown, factories and nightclubs, but also safe, clean, and affordable. More importantly, its lobby restaurant provides "authentic Taiwanese dishes and snacks." 
Being one of the only two Taiwanese cuisine restaurants in the city between 1998 and the early 2000's, the hotel's restaurant is the major social space for the Mandarin-speaking community in all Phnom Penh (The first Taiwanese Cuisine restaurant is Ching-ye Loco Restaurant, while currently there are more than 10 other places: Du Xiaoyue, Manhan Lou, Lukang Eatery, Hongshun Diner, Xiaoyue Eatery, Chunghsin Cafe, Zhuojia Beef Noodles, Golden Diamond Beef Noodles, Emperor Pig Feet, Lailai Eatery, Guobin). As of 2013 and 2014, Chung Hsin Hotel and the street blocks around it (near Kampuchea Krom Blvd and $225 \mathrm{St}$.) have developed into an ethnic ghetto with 3 hotels, 3 Taiwanese restaurants, two grocery stores, 1 bubble tea house and 2 KTVs, all targeted at Chinese-speaking consumers. Chung Hsin Hotel is still the most popular choice for short term stay-over business travelers, such as foreign quality controllers (QC) of garment factories.

Furthermore, the private dining room of Chung Hsin Hotel's restaurant has been the meeting room and social center for the Taiwan Commercial Association in Cambodia (TCAC) and its members since its opening. The restaurant's managers and co-owners have all played important roles in TCAC as well. The most significant case may be TCAC's formal General Manager (1998 2008) and the current co-owner, Mr. Jin Yonxing. Besides serving as Chair of TCAC for two terms (2004 2008), Mr. Jin was also appointed by the Taiwanese Government as Overseas Chinese Affairs Commissioner, an un-paid honorary position yet highest official representative of the Republic Of China (Taiwan) in Cambodia. Since Taiwan does not have official or semi-official offices in Cambodia due to the lack of formal diplomatic relationship, Mr. Jin is usually respectfully seen as Taiwan's official representative at most occasions.

In addition to the Chung Hsin Hotel, other major periphery social spaces for Phnom Penh's Taiwanese include Guo-bin Motel, TCAC office, a dozen of popular Taiwanese Restaurants and KTVs, two collective residential communities (Bali Apartments I \& II and New World), and several other private residences of key/senior/famous Taiwanese entrepreneurs. Unlike Chung Hsin Hotel as a major social/gathering choice in the Phnom Penh's Taiwanese community, these periphery/satellite social spaces offer alternatives for sub-social groups connected by age, professions, hobbies, social status, friendship or simply geo-spatial connections. These sub-social groups are not attached to a specific social space, and tend to be informal and semi-open for newcomers, as long as they are introduced/ brought in by an old member. Many field stories and my field experiences show that most of Lao-Taishang or Lao-Jinbian (Old Taiwanese businessmen/Old Phnom Penh) act very cautious and reserved when meeting a newcomer, therefore, for a new member to join the sub-social groups, he/she is always introduced/brought in by a current member.

Taking the so-called Guobin Gang as a sub-social group example, this informal social group with 16 core members is based at the living room /office of Guobin Motel on the Russia Blvd near Pochentong International Airport. Opened on April 10, 2003 by one of the earliest Tai-shang, Guobin Motel is now managed by Chen's son, Chen Chihcheng and his Sino-Khmer wife Chhuor Davy. It was actually the first drive-in, garage-room motel in the Cambodia. With its novel business model and location between the industrial zone and downtown, it soon became an alternative accommodation option for Phnom Penh's Taiwanese mid-level managers. Gradually, it became one of the most important social spaces for 16 Tai-Shangs (age between 25 to 40), or said to include 6 to 8 households who are all long-term Taiwanese residents in Phnom Penh. Guobin Gang members include the owner of Taiwanese cuisine restaurant, the biggest Taiwanese grocery supplier in Phnom Penh, several migrated youth, several senior Taiwanese administrative workers of shoe, garment, textile factories, plus their spouses and children. Guobin Gang has become an identity term within the Taiwanese community.

Chung-Hsin Hotel has been the most important social space for all Taiwanese in Phnom Penh, even in Cambodia; Guo-Bin Motel has become the central gathering location for quite some Tai-shangs too. Both Chung-Hsin's and Guo-Bin's owners/acting managers (Mr. Jin and Chen's couple) play multiple important roles in Phnom Penh's Taiwanese community too. The correlation between the emergence of central social space and the leadership of local ethnic organizations, thus attracted my interests in 
understanding the causal effect/emerging process in two major aspects. First is how an ethnic social space emerged in the first place, and the second one is how its members then initiated, institutionalized, and legalized the informal gathering into formal ethnic associations. Take TCAC as an example here, how does Chung Hsin Hotel evolve into being the central social networking space among Taiwanese in Cambodia? How does TCAC start to tie up with a private sector (Chung Hsin Hotel) while TCAC does have its own office? And what role does Chung Hsin Hotel play in TCAC's developmental process? Does this correlation between primary social location and ethnic institutionalization apply to other ethnic Chinese organizations in Phnom Penh?

\section{From Social Grouping to Ethnic Organizations: Dynamic Case of Mainland Chinese in Cambodia}

Mainland Chinese started to move to Cambodia since 1993, the number boomed rapidly after Go-Out Policy was announced in 1997. Up to May 2014, there were 12 regional Chinese Chamber of Commerce in Cambodia under the umbrella of the national Chinese Chamber of Commerce in Cambodia (CCCC). CCCC was first established in 1996 as a transnational social platform to facilitate information exchange and emergency relief coordination by 20 Chinese state-owned corporate leaders. It has been led by Chairman Mr. Gao and has been the major venue for Chinese business leaders to connect with Sino-Khmers, government officials in Cambodia. Unlike CCCC's formal institutionalization, the institutional levels of the 12 regional business organizations vary by their size, leadership style and strategic missions. For example, Wenzhou Chamber of Commerce in Cambodia, a.k.a. Wenzhou Shanghui is famous for its member cohesion, hierarchical division, financial function and global Wen-Shang networking. Several key members of Cambodia's Wenzhou Shanghui even initiated a 4 million global joint venture to open the Jiănpǔzhài Wēnzhōu dà jiǔdiàn in 2012. ${ }^{2}$

On the other hand, some regional business associations/Shanghui serve more like semi-formal or informal social groups in which members meet irregularly or once to twice a year. The Shanghui leaders print their titles on the organizational name cards so they can raise or recruit new business partners or investors in their hometowns, or apply to get possible honorary positions from the local OCAC office. This may be useful for them to get a loan in their hometown as well. However, most mainland Chinese entrepreneurs in Phnom Penh are not aware of those organization's operations and personnel. They may just have heard of it from organizational title online or on CCCC's website (by author's Interview with informants). Some of these so-called Shanghui may actually only be active in somebody's living room. Unlike the well-established Shanghui that have their own organizational offices (such as TCAC, CCCC, Association for Chinese in Cambodia, Cambodia's Wenzhou and Zhejiang Shanghui), most Chinese regional Shanghui do not have a fixed office location or central social space- the Shanghui office oftentimes is located in the new Chairperson's office or residence.

The rapid growth in number of business organizations among mainland Chinese in Cambodia since 2012 is a note-worthy phenomenon. It shows that mainland Chinese in Cambodia have accumulated to a certain size in Phnom Penh, in contrast to the previous model of individuals fighting their way out and trying to survive in a foreign country. It's clear that mainland Chinese in Cambodia are at the beginning stage of forming their collective identities and social belonging in expanding their personal network, integrating their venture resources, consolidating group power, and further formalizing their economic capital into social and political capital. In other words, all those active engagements of social life through this traditional same-industry (tongye) and same-hometown (tongxiang) networks on a foreign soil not only enhanced their social network in this ethnic group but also extended their personal network into public and political areas. Moreover, as what I have addressed in previous articles on the roles of ethnic organizations playing in the cross-strait Overseas Chinese affairs in Cambodia; these ethnic business organizations can be viewed as the extension of the competition between China and Taiwan.

The interpersonal interactions through business or other organizations within the mainland Chinese community not only enhanced the traditional ethnic ties, but also shaped the structure of the early Chinese migrants' social/political network. This ethnic network of social organizations can be seen as a new 
version of Silk Road development in the $21^{\text {st }}$ century. This article focuses on how these business organizations were initiated and evolved from the location/social space based social gathering into well-structured organizations.

\section{The Initiation of Mainland Chinese Business Organizations and its Correlation with Social Spaces and Groupings}

Since I started my research and participatory observation on the Chinese community in Cambodia in 2006, I have focused on its social structure and ethnic organizations, especially after my long-term fieldwork in Phnom Penh. The rapid change in the structure of the mainland Chinese community in Cambodia then has provided an extremely vivid and yet astonishing example in understanding how a migrated community emerged and developed its inner political and social structure. Compared with Sino-Khmer and Taiwanese communities in Cambodia, the early stage of social initiation and grouping dynamics in mainland Chinese community shown in 2006 2014 can be seen as a great process of diaspora's self-governing. Unlike the more static and mature ethnic-political structures of Sino-Khmer and Taiwanese communities in Cambodia, the sub-ethnic hierarchy among mainland Chinese is still evolving. This article also focuses on the historical background and developmental process of ethnic organizations among mainland Chinese community in Cambodia. Supported by numerous sub-ethnic grouping cases, five types of social organizations are defined and classified in understanding the development of the sub-ethnic groups within mainland Chinese community. Each of these five grouping processes is discussed below.

\section{Virtual Community of Overseas Chinese Networks}

Since its first establishment in 1999, the Chinese instant messaging software Tencent QQ has been the most important social platform for most of Chinese youths. Seen as China's MSN, QQ has dominated $64.7 \%$ of China's instant messenger market since 2005 and currently owns $86.9 \%$ of mobile device's IM market share. ${ }^{3} \mathrm{QQ}$ along with Wechat (Weixin, founded in 2011), another IM software created by the same corporation Tencent, were two major platforms for Chinese's virtual communities until Wechat dominated the market before 2016. This is especially important for Overseas Chinese, because most of them used QQ to maintain connection and interaction with their business associates, families, friends and their internet contacts.

Among mainland Chinese in Cambodia, QQ was also the major communication channel, even Sino-Khmers who adapt Chinese as the first language use QQ widely too. I applied a QQ account and have been using it to keep contact with my Chinese or Sin-Khmer friends since 2008. "What is your QQ number?" is usually the ending question that I raise everywhere in Cambodia after I meet new friends. After I started using it, I soon discovered that QQ Groups have created a new type of social platform for people to build connections and reach out for new friendships. Therefore, I started to follow and observe how mainland Chinese and Sino-Khmers use QQ Groups to exchange information, make new friends, explore new market, reconnect with old acquaintances, or reconcile resources.

Simply search Cambodia in Chinese (柬埔寨) in QQ groups; the search results yield 462 groups with member size ranging from 1 member to 901 at most. If searching by Phnom Penh in Chinese (金边), 370 groups (with member number from 1 to 494) can be found in all sorts of topics (both searched on October 20, 2014). Since 2009, I have started to follow 30 groups that are most active and have the highest members. Many members in those 30 QQ groups are overlapped and many accounts are simultaneously active in various groups. Anyone with a valid account can start an interest group by labeling the title and setting up the group description, while the administrator of the groups can regulate membership in three different style: Open access (open group), Enrolled with admission (semi-open group) and By invitation only (Closed group). Among these 30 QQ groups, 9 are semi-open groups and 21 are open access groups. 
Those QQ groups not only provide a virtual space for members to interact and make connections with their old acquaintances in traditional Five Commonality network (people who are connected in the following five ways): hometown, classmates, coworkers, surname, or interests. Meanwhile, these open-access QQ groups with loose membership tend to serve all kinds of modern social purposes: information or help seeking, sharing, business promotion, sex/one-night-stand/relationship matching, job hunting, business opening, online frauds... etc. These Cambodia-related QQ groups are the first step of social grouping for people who have been to, never been to, planning to go to or even just interested in Cambodia or curious about Angkor Wat. As long as they have a valid QQ account and can speak and type in Chinese, they can always find a group for themselves, no matter how their relationship with another group member plays out. For example, QQ groups for people from the same corporations such as: textile mills, shoe factory, restaurants, construction companies, farms, land developers, trading companies, Chinese schools, bookstores, mining companies, marriage agency, interior design and decoration, foresting, small commodity trading, human resources, translations, travel agency, religion units,... etc. tend to be semi-open or closed groups, while hobby/ interest groups such as those in gambling, ethnic food and restaurants, badminton, soccer, basketball, ping pong, language learning, writing, investment, prostitution, anti-union, outdoors, touristic... etc. tend to be open ones. Groups with specific qualification such as those of Five Commonalities tend to have firm membership and are most likely to be semi-open or closed groups while the group administrator may conduct an identity check once a while to delete "unwelcome accounts." For instance, QQ groups of Jiangxi Hometown Association and Guangdong Shanghui make it clear in the group description that every member should state his/her real name and hometown cities in their group name cards. My enrollment application to some other QQ group like that of Cambodia Shaowu Hometown Association (with 29 members) was denied simply because of "Who are you? Don't recognize you!" while I was also accepted to closed QQ groups like groups of Cambodia's Shanxi Laoxizngqun (100 members), Cambodia's Zhuji Tongxianghui (17 members) and Cambodia's Chengdu Qun (36 members).

Overall, this type of social groups are the earliest grouping experience for people who are interested in Cambodia no matter where they were, or how they related to Cambodia or Chinese community. These virtual communities are the weak social ties that are organized and operated beyond national borders. It is a new way of communication that connects anyone from anywhere who is willing to connect with others who share the same interest, identity or belongingness beyond national border. Like Liu Hong (1998) and McKeown (1999) both pointed out that this virtual social network could be seen as another form of daily practice of the ethnic network that move from de-territorialization towards a new globalization era.

\section{Substantialization of Social Groups and Space: In-Person Interaction}

Unlike the anonymity and loose membership in the virtual communities, the other type of early social grouping within Overseas Chinese diaspora community in Cambodia is in-person onsite socials that are carried out as a kind of daily practice of social Substantialization. Similar to how creolization is a mixture and relational process between cultural globalization and ethnic authenticity (Arends, 1996; Stewart, 2007), social substantialization refers to the interactive process of group members to de-virtualize from an online social group or distant networking into physical activities. Traditional business convention has it as Yìngchóu or Qǐngkè chīfàn for meeting new business associates, potential partners, reconnecting friends and old acquaintances, or meeting friend's friends just for expanding social network. In the modern cyberspace era, Wăng jù, or Wăngyǒu jùhuì in full and Qún jù, or group friends get together in full, have become the new trendy term for networking. These social group meet-ups take place as irregular and occasional get-together dining, singing KTV, or hanging out in some coordinator's office or living room.

In the case of Chinese citizens in Cambodia, this type of early stage social grouping is extremely important since most mainland Chinese sojourners in Cambodia do not speak any Khmer and most of them moved to Cambodia for economic and the open environment reasons. Most of my mainland Chinese interviewees reflected similar migration stories to my question of "why did you decide to come to 
Cambodia at the first place?" They may have different reasons to stay and start a new career in Cambodia but many of them were brought to Cambodia for the same reason. These Chinese businesspersons went to Cambodia mostly due to job assignments in their early years before deciding to stay and seeking a new career on the new soil. The jobs that brought them to Cambodia were usually related to Chinese language education system, state-owned businesses, sub-constructors, or shoe and garment factories. After they settled down, these new settlers mobilized and recruited their friends from hometown in China to Cambodia. Their social cycles tend to be small, limited, closed, and isolated from local Cambodian society since rarely any of them speak or want to learn Khmer. Some of my mainland Chinese interviewees who married Cambodian females they met in the workplaces do speak conversational Khmer. Thus, meeting new Chinese friends and homies/ homeboys through friend's introduction or internet groups became the major and perhaps the only way to extend their social cycle or develop business. This is also why many of my interviewees said that they only started to join these local ethnic groups, organizations or traditional networks after they went to Cambodia.

The membership of these types of social groups is usually semi-open to anyone with proper reference or existing connection from certain social platforms, both virtually and non-virtually. It is easier for member to understand and establish the trust since they could know and predict from each other's background, or as my interviewee Lu Wei puts it as Zhīgēn zhīdǐ (know one's root, know one through). Membership in this type of social groups is usually flexible and floating. The organizer and the first meeting are both very critical for further development of the social group. I went to several such meetings in Phnom Penh that ended up awkwardly. Meanwhile, I also got a chance to have participatory observation of the first QQ group meeting of Jiangxi Tóngxiānghuì in January 2014 at Laodefan Resturant and it gradually turned into a formal regional chamber of commerce as Cambodia's Jiangxi Shanghui later in June 2014. Another successful case is the owner of Cambody Cafe, Liu Ye and several QQ groups that he established, and later he and his group mates started to meet regularly and occasionally in his store.

To sum up, this type of social grouping occasionally carried out on the ground of existing networks among different people's personal five-sameness (Wǔ tóng) connection. Or it is used to extend and substantialize personal identities into social capital. It represents how the friendship originally existed in personal networking starts to substantialize into in-public meeting, gathering, and more engaging activities. And oftentimes, this stage of social grouping could be coincidentally and simultaneously implemented with business meeting, socials, or any personal life events without any planning and coordination.

\section{Normalization of the Chinese Sub-Groups: Location, Membership and Group Routines}

The third type of social grouping observed from mainland Chinese communities in Cambodia is how each social group starts to normalize into regular and routines with members, meeting location and activities. At this part, one or more dedicated and enthusiastic leadership with fixed social space will emerge along with the development of group routines. As the members of the group start to settle down with regular individuals periodically, common membership and regular social events soon sublimate toward Jiāoqing (personal relationship). At this stage, it could be considered as the social dynamics of belongingness and ethnic identity as Phinney and Ong pointed out in their 2007 article (Phinney \& Ong, 2007; also see Phinney, 1992; Yip \& Fuligni, 2002; Lee \& Yoo, 2004).

These social groups can be viewed as organisms; they evolve over time; and their members' group identity and sense of belongingness grow with it. The social groups among Chinese in Phnom Penh usually contain 4 to 8 core families or individuals along with twice the amount of active regular members and another twice amount of occasionally-attending inactive members ( 1 core : 2 active : 2 inactive). In addition, as each individual can belong to multiple formalized groups with different levels of engagement it is difficult to estimate the exact number of this type of social groups in Phnom Penh. The number could vary from hundreds to thousands among the 100,000 mainland Chinese in Phnom Penh. My field work 
experiences with Xu's Literati Gang (couple and Family oriented gathering), Gao Feng \& his JWM Industry Group Co. LTD. Associates (all single male factory staffs) and the Volunteering Chinese Teachers in Phnom Penh mostly young female graduate students)] can be three excellent and very different examples to match this type.

\section{Formalization of Organization Structure: Organizing and Leadership}

The continuity and substantial development of a social group not only rely on its enthusiastic member engagement, but also the dedicated leadership that sustains the group's operation and growing. It requires a large amount of resources and logistics management, which are both time and money demanding. Therefore, thousands of social groups in Phnom Penh can form and soon fade away without anyone's notice. Only very few maintain long term operation and continuous growth into the next type of social group - formalizing into an organization with the full body of administrative structure and leadership with regular meeting location and annual events. Among all sub-ethnic Chinese communities in Phnom Penh, a few nameable sub-groups turned into more structured organizations. Taking Taiwanese community as an example, there are 12 Sisters, Jinbian Taishang Golf Team, Jinbian Youth Club, Taiwanese Garment-textile industrial Union, TCAC Youth Division and TCAC-Hakka Committee. Even though they were not operated nor registered as formal organizations and usually do not reach out for member recruiting, they all have clear leadership, membership pool, group events and at least one regular meeting location.

In Phnom Penh's mainland Chinese community, many formalized sub-organizations are business and economic oriented interest groups, such as the Cambodia China Economic Development Alliance. Also there are several groups that are also hometown association with limited members and do not have sufficient resources to mobilize the group into a full legalized organizations, like Cambodia Shaanxi Hometown Association and Northeast Hometown Association. However, four basketball teams that are affiliated with specific factories or corporations provide different examples. They have clear group identity, leadership, membership, routine events, particular social space and even funding for the teams. But they would not, in most case, legalize into a formal organization in affiliation with any transnational or local political structure, even if they are more formalized than those loose substantialized social groups. Taking the crowd of Gao Feng \& his male coworkers from JWM Industry Group Co. LTD as an example, Gao Feng and his associates did not have clear leadership structure, group routine, and a common course/purpose, however, they had stable membership pool and hang-out after work regularly. Therefore, formalization of organizational structure and operation with explicit leadership, membership, common course/mission, and a stable funding are essential factors for a loose social organization to turn into a sustainable ethnic organization in the migration community.

\section{Legalization of Chineseness on Business: Transnational Civil and Ethnic Registration and its Politicization}

Based on the transnational structures of Overseas Chinese affairs among Cambodia, China and Taiwan that are discussed in previous articles, the current structure profoundly echoes Pierre Bourdieu's concept of cultural agent theory: the cultural habitus, field and capital (1979). The Chinese ethnic organizations in Cambodia can be seen as the key agents for members to socialize their ethnic identities in the transnational diasporic field. Variations of member's internalized relationship in those organizational agents can be seen as the dots; and the self-governing of group dynamics that derive toward the "habitual expectations" within the diaspora communities can be seen as the lines on the blueprint in understanding how a new migration community eventually evolves into the static ethnic ecology on the new soil.

In this sense, the legalization process of those ethnic organizations in Chinese diasporic community is the last piece of puzzle to complete the picture. By legalization, the organizational status with dual reorganizations from sojourn and home state authorities, members and leaders of these organizations politicize their social capital into political assets. For example, each of 12 regional Chambers of 
Commerce has to register with the Chinese Chambers of Commerce in Cambodia and China's Embassy in Cambodia after gaining support and permission to establish from the Association of Chinese in Cambodia. At the same time, those commercial leaders will also visit and strive for the political and financial support from their hometown authorities, both provincial and municipal. A lot of time, provincial or local Overseas Chinese Affairs office will be designated to be the administrative office for their application and bureaucratic management in the future. Leaders of these regional Chambers of Commerce usually will also be honored with certain titles, both official and non-official ones, such as local Zhèngxié wěiyuán. This is not simply just Yìjīn huánxiāng or Róngguī gùlǐ (return to one's old home town in full glory), but also the political capital that can help them access elite networks, and establish creditability and reliability on fund raising and joint venture in both China and Cambodia.

Up to October 2014, there were 12 Chinese regional Chambers of Commerce in Cambodia, and they were all registered under the central Chinese Chamber of Commerce in Cambodia, CCCC. All of these 12 regional Chambers of Commerce were established after 2011. Although each of them could vary in all aspects and operative details, but the common characteristics of those organizations are based on member's regional identities and organization's business orientation. Beyond business organizations, the only non-commercial organization is Cambodia Council for the Promotion of China Peaceful National Reunification, a political organization in favor of China and Taiwan's unification and anti-separatism. Other than that, there is no other type of formal social or ethnic organization in the mainland Chinese community in Cambodia. My participatory observation with the Jiangxi Tongxianghui/ Shanghui can provide a great example of an organization went from an online QQ group, after the substantialization, normalization, formalization and then legalization into an official regional Chamber of Commerce in 9 months.

\section{Conclusion: The Life Cycle and Group Dynamics of Business Organizations in PP and the Ethnic Power}

As a static picture of Taiwanese community's social space and organizations in Cambodia is described in the prior part of this article, the second part of this article turns the attention toward the grouping dynamics of Mainland Chinese community in Cambodia. It is understandable since the community of Taiwanese in Cambodia has developed for more than 20 years when the first wave of Tai-Shang settled down after United Nations' intervention and peacekeeping acts in 1992. Taiwanese community is a relatively small and stable migrated community along with the up and down of Taiwan's economy and its diplomatic relation with Cambodia. The mainland Chinese community in Cambodia, on the other hand, has been a new and yet still developing migrated community since 2002. It grew more rapidly and vitally than any other migrated or ethnic communities in contemporary Cambodia due to China's comprehensive strategic partnership with Cambodia in all dimensions, along with Cambodia's open door policy and Chinese-friendly environment. The author tries to compare Taiwanese and Mainland Chinese communities not only because both are considered Huárén (Chinese) but they are both economic migration and share the similar cultural background, while they started and developed in different chronicle order. Therefore, an analytical comparison of the both communities' development pattern is highly valuable for diasporic theories.

Following this logic, the main discourse we attempt to generalize from the ethnographic data the author collected and presented in this article is the correlation between the ethnic life circles and the organizational life cycle. If the present social and organizational status of Taiwanese Diasporas in Cambodia can be seen as a mature and stable sub-ethnic community, can we apply the path and variation of social grouping in the Cambodia's mainland Chinese community as a procedural paradigm to understand how it evolved over time?

For example, if we look into the affiliating social space of different regional Chinese business organizations in Phnom Penh like the Taiwanese subgroups we analyzed in the first half of this paper, we can find a similar development pattern in many mainland Chinese regional business organizations. That 
explains how different types of these ethnic organizations were firstly substantialized in several regional cuisine restaurants (see Table 1 below). For example, Shanghai Chamber of Commerce in Cambodia was based on the most famous Shanghai restaurant in Phnom Penh, Yì xiān lóu Restaurant. The restaurant owner Mr. Ni Hongsheng is also the founding member and current president of this Chamber of Commerce since it was established in 2012. Chongqing Fish Restaurant and Sichuan and Chongqing Chamber of Commerce, and Wenzhou Grand Travel Agency or Wenzhou Sanlin Restaurant and Wenzhou Chamber of Commerce are other significant examples for the relationship between the regional-cuisine restaurants as meeting space and geographical subgroup's development.

TABLE 1
LIST OF SELECTED ORGANIZATIONS AND THEIR MAJOR SOCIAL SPACES

\begin{tabular}{|c|c|c|}
\hline Organizations & $\begin{array}{c}\text { Major/Core Social Space/ } \\
\text { Centrality }\end{array}$ & Satellite Social Spaces \\
\hline $\mathrm{CCCC}$ & $\begin{array}{c}\text { Phnom Penh Grand Hotel、Old } \\
\text { Place Seafood Restaurant }\end{array}$ & -- \\
\hline $\begin{array}{l}\text { Shanghai Chamber of } \\
\text { Commerce in Cambodia }\end{array}$ & Yì xiān lóu Restaurant & -- \\
\hline $\begin{array}{l}\text { Cambodia Hunan Chamber } \\
\text { of Commerce }\end{array}$ & Hongyu Supermarket & -- \\
\hline $\begin{array}{l}\text { Cambodia Sichuan and } \\
\text { Chongqing Chamber of } \\
\text { Commerce }\end{array}$ & Red Dragon Restaurant & $\begin{array}{l}\text { Chongqing Fish } \\
\text { Restaurant }\end{array}$ \\
\hline $\begin{array}{l}\text { Cambodia Zhejiang } \\
\text { Chamber of Commerce i }\end{array}$ & Red Dragon Restaurant & $\begin{array}{l}\text { Factory area of Dannu } \\
\text { Combodia Clothing } \\
\text { Limited Corporation }\end{array}$ \\
\hline $\begin{array}{l}\text { Cambodia Wenzhou } \\
\text { Chamber of Commerce }\end{array}$ & $\begin{array}{l}\text { Wenzhou Grand Hotel (Closed } \\
\text { due to Property Dispute) }\end{array}$ & $\begin{array}{l}\text { Wenzhou Sanlin } \\
\text { Restaurant }\end{array}$ \\
\hline $\begin{array}{l}\text { Cambodia Guangxi } \\
\text { Chamber of Commerce and } \\
\text { Hometown Association }\end{array}$ & $\begin{array}{l}\text { Yushanlou Restaurant (Phnom } \\
\text { Penh)、 Woodhouse Restaurant } \\
\text { (Siam Reap) }\end{array}$ & $\begin{array}{l}\text { Juguiyuan Restaurant、 } \\
\text { Shiweitian Restaurant }\end{array}$ \\
\hline
\end{tabular}

Like Chung Hsin Hotel and several satellite ethnic dining/social spaces can be tied with Taiwanese organizational development (TCAC and Guobin Gang et al.), many regional cuisine restaurants in Phnom Penh are the starting places and/or central social spaces for groups based on regional and dialect identities. Even though the relationship between social space and ethnic organizations are still under development within mainland Chinese community in Cambodia, there is a clear pattern of some ethnic organizations settlement with a core meeting location, while other informal/casual social groups may have several satellite social spaces.

The correlation and causality between dinning places and sub-ethnic social groups is not definite, especially with Chinese immigration's explosive growth after 2016. Restaurant owners and managers usually play very important role in those ethnic organizations, but it may be just similar to the cases that 
David Y. H. Wu and Sidney Cheung presented in their 2002 and 2014 books. The atmosphere and spatial settings of Ethnic Cuisine and its additional social function of folks with the some hometown nostalgia is an essence of collective actions. Such collective actions of identity making reflect on the social engagements of organizational behaviors, as well as personal capital transformation from daily consumption decision making to networking. The case therefore presented here in the article with the comparison of the Taiwanese and Mainland Chinese communities may be just an evidence of $\mathrm{Wu}$ and Cheung's claim of "functional interconnections between food systems and other subsystems of the society (Cheung and Wu 2014: xviii)." In Cambodia, these ethnic social groups may start from a virtual community pursuing the nostalgia solution with their hometown cuisine, while dialects and hometown atmosphere are recreated in the restaurants in a foreign country. The forming and development of socio-ethnic organizations beyond borders thus can be seen as in figure 1 below.

\section{FIGURE 1}

\section{TRANSNATIONAL SYSTEM OF SOCIO-ETHNIC SPACING, ORGANIZATION AND} NETWORK

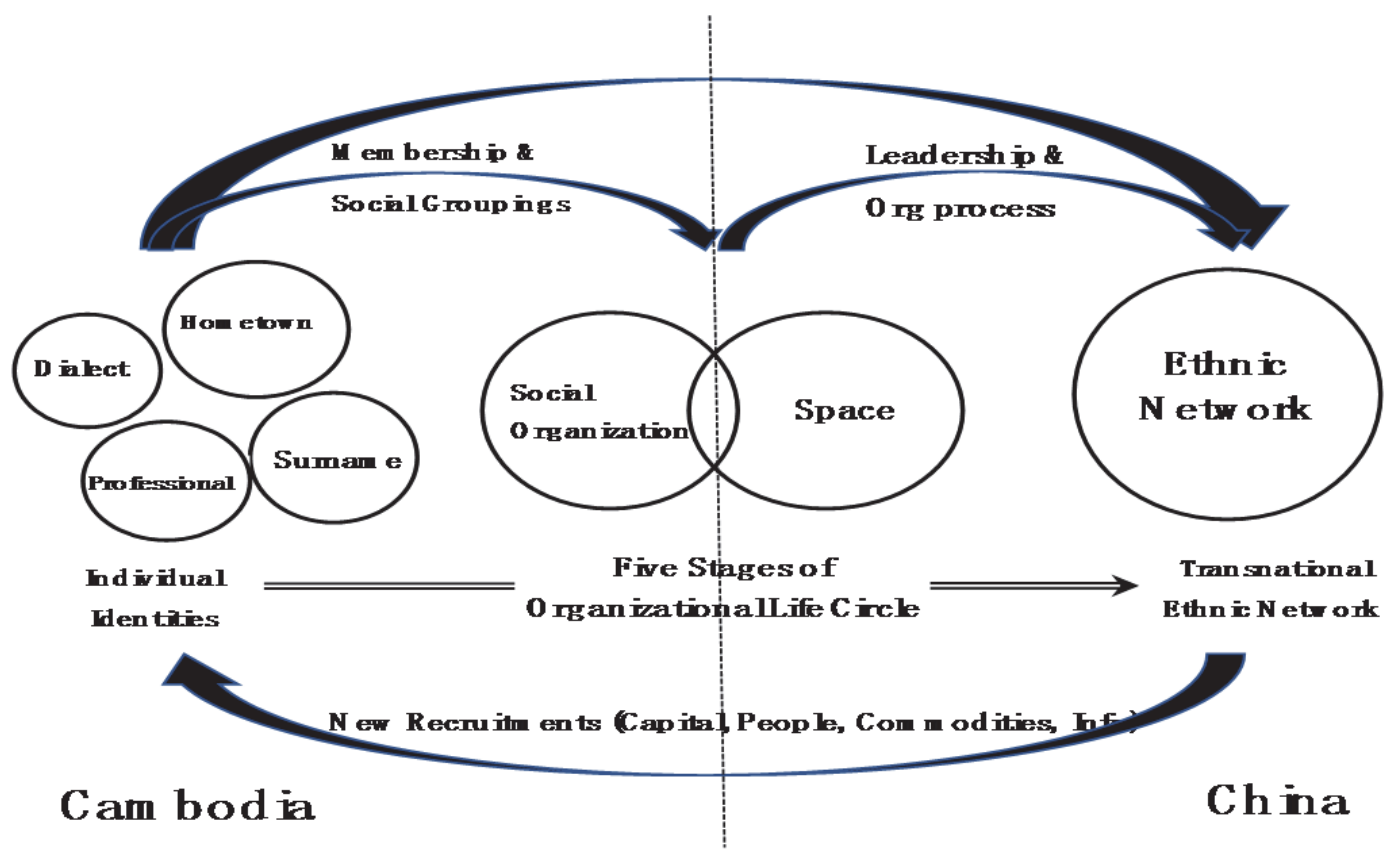

The systematic connection of social spacing, organizational life cycle and ethnic network utility of the Chinese business organizations in Cambodia can be portrayed as a system in the Figure. Individual identities from various sub-ethnic groups in the Chinese communities in Cambodia are the basic elements and personal social capitals for members to use in engaging others in the remote soils. Different levels of these social engagements have then displayed in five stages discussed above. Ethno-social organizations and spaces can be seen as both of the platform and the institutions for individuals to situate themselves with personal identity assets. The process of these social grouping developments from informal to formal or even legal status operates beyond national boarders and sovereignties between Cambodia and China. The formalization and legalization of Chinese ethnic network through social organizations between two countries then can be endorsed by both economic and political institutions to generate into the reliability 
and trust convenience for the new recruitments of new capitals, investments, business opportunities, and personal connections. Therefore, the formal and informal cost of these organizational participations is not only early investment but also the method of personal capital transformation from personal identities to social, economic and possible political capitals in both countries.

To conclude, this article is aimed at putting together all the puzzles of the life cycle of ethnic organization and how it is connected with specific social spaces. With all the ethnographic data the Author collected from Cambodia's Chinese communities, this article also attempts to theorize the correlation between members, social space and organizations in different stages. It firstly looks into the social structure and space of a relatively mature sub-ethnic community, Taiwanese community in Cambodia. Taiwanese case then provides a baseline and complete ethnic ecology for the readers to understand how a static diasporic community can be after more than 20 years of development. Next, the author applied the preliminary paradigm of ethnic organization life cycle on the mainland Chinese in Cambodia in comparison. Mainland Chinese community in Cambodia is a newly booming migrated community with its own community order still in development. This dynamic force can be viewed as the soft ethnic power that drives Chinese in Cambodia to establish the ethnic network transnationally. While our attention has been focusing on the economic and cultural power of Chinese community, we may now need to shift part of our attention. The ethnic power and civil force that exists in the overseas Chinese community, and how global overseas Chinese community united as a global ethnic network entity are both issues worthy of our attention. This ethnic power then could be what really defines China's soft power and the fifth force for the new Silk Road Era besides those of economy, politics, diplomacy, and media.

\section{ENDNOTES}

1. Shihlun Allen Chen is Associate Research Fellow at Center for Overseas Chinese Studies and Center for Southeast Asian Studies, School of International Relations, Sun Yat-sen University.

2. Although it was shut down on January 16, 2014 by the court order due to ownership disputes between the new and old owners. The biggest and once the most promising joint capital of Mainland Chinese businessmen in Cambodia soon became a legal and social disaster since everyone involved tries to influence the verdict toward their own interests by pulling strings.

3. CNNIC. Di 42 ci Zhong guo hu lian wang luo fa zhan zhuang kuang tong ji bao gao (The 42th Investigation Report on the Situation of the Development of Internet Network in China). http://www.cac.gov.cn/2018-08/20/c_1123296882.htm. 


\section{REFERENCE}

Arends, J. ed. 1996. The Early Stages of Creolization (Vol. 13). John Benjamins Publishing.

Cheung, S. and Wu, D. Y. (eds.). 2014. Globalization of Chinese Food. Routledge.

Liu, H. 1998. "Old Linkages, New Networks: The Globalization of Overseas Chinese Voluntary Associations and its Implications." The China Quarterly 155, 588-609.

Liu, H. 2005. "New Migrants and the Revival of Overseas Chinese Nationalism." Journal of Contemporary China 14(43), 291-316.

MacDonald, J. S., \& MacDonald, L. D. 1964. "Chain Migration Ethnic Neighborhood Formation and Social Networks. The Milbank Memorial Fund Quarterly 42(1), 82-97.

McKeown, A. 1999. "Conceptualizing Chinese Diasporas, 1842 to 1949." The Journal of Asian Studies, 58 (2), 306-337.

Landa, J. T. 1994. Trust, Ethnicity, and Identity: beyond the New Institutional Economics of Ethnic Trading Networks, Contract Law, and Gift-Exchange. University of Michigan Press.

Lee, R. M. and Yoo, H. C. 2004. "Structure and Measurement of Ethnic Identity for Asian American College Students." Journal of Counseling Psychology 51(2), 263. PP??

Parkins, N. C. 2010. "Push and Pull Factors of Migration." American Review of Political Economy 8(2), 6.

Phinney, J. S. 1992. "The Multigroup Ethnic Identity Measure a New Scale for Use with Diverse Groups." Journal of Adolescent Research 7(2), 156-176.

Phinney, J. S. and Ong, A. D. 2007. "Conceptualization and Measurement of Ethnic Identity: Current Status and Future Directions." Journal of Counseling Psychology 54 (3), 271.

Redding, G. 1995. "Overseas Chinese Networks: Understanding the Enigma." Long Range Planning 28(1): 61-69.

Stewart, C. ed. 2007. Creolization: History, Ethnography, Theory. Left Coast Press.

Wu, D. Y. H., \& Cheung, S. C. 2002. " "The Globalization of Chinese Food and Cuisine." The globalization of Chinese Food, 1-18. 